\title{
A STUDY OF QT DISPERSION AMONG TYPE 2 DIABETICS ATTENDING A TERTIARY CARE HOSPITAL IN PUDUCHERRY
}

Yogesh $S^{1}$, Uthaya Sankar M. K2, Shenbagaram $K^{3}$, Hanushraj $R^{4}$

1Postgraduate Resident and Principal Investigator, Department of Internal Medicine, SMVMCH, Puducherry, India.

2 Professor and Unit Chief, Department of Internal Medicine, SMVMCH, Puducherry, India.

${ }^{3}$ Assistant Professor, Department of Internal Medicine, SMVMCH, Puducherry, India.

${ }^{4}$ Senior Resident, Department of Internal Medicine, SMVMCH, Puducherry, India.

\section{BACKGROUND}

ABSTRACT

Increased QT interval dispersion (QTD) has been commonly found among type 2 diabetes mellitus.

Aims and Objectives- The aim of the study is to find out the prevalence of QT dispersion in type 2 diabetes mellitus in a tertiary care hospital.

\section{MATERIALS AND METHODS}

QTc is measured through Bazett's formula and QT dispersion is calculated in a total of 80 outpatients and in patients with type 2 diabetes mellitus at a tertiary care hospital between October 2017 and December 2017 and to compare with controls.

\section{RESULTS}

Case subjects has $40 \%$ of QT dispersion (32 out of 80 subjects) compared to the control has $22.5 \%$ of QT dispersion (18 out of 80 subjects, that is $17.5 \%$ higher than control group).

\section{CONCLUSION}

Hence, subject with diabetes mellitus has more chance of cardiovascular disease than non-diabetes subjects. QT dispersion helps in identifying the cardiovascular disease as early as possible.

\section{KEY WORDS}

Type 2 Diabetes Mellitus, QT Dispersion, Poor-Man's Treadmill Test.

HOW TO CITE THIS ARTICLE: Yogesh S, Sankar UMK, Shenbagaram K, et al. A study of QT dispersion among type 2 diabetics attending a tertiary care hospital in Puducherry. J. Evolution Med. Dent. Sci. 2018;7(23):2773-2776, DOI: $10.14260 /$ jemds/2018/626

\section{BACKGROUND}

Cardiovascular disease (CVD) is now the most common cause of death worldwide. Before 1900, infectious diseases and malnutrition were the most common causes and CVD was responsible for less than $10 \%$ of all deaths. In 2010, CVD accounted for approximately 16 million deaths worldwide (30\%) including nearly $40 \%$ of deaths in high-income countries and about $28 \%$ in low- and middle-income countries. ${ }^{1}$

There are multiple risk factors for cardiovascular disease; of the most important one is diabetes mellitus. ${ }^{2}$ An estimated 346 million people worldwide have diabetes. The International Diabetes Foundation predicts that this number will reach 522 million by 2030, a yearly rate of growth that is higher than that of the world's adult population. ${ }^{3}$ QT dispersion in ECG is considered as poor-man's treadmill test, which is used to find out any cardiovascular abnormalities in those patients with abnormal ECG that can be considered for coronary angiogram. ${ }^{4}$

'Financial or Other Competing Interest': None.

Submission 22-02-2018, Peer Review 19-05-2018,

Acceptance 28-05-2018, Published 04-06-2018.

Corresponding Author:

Dr. Uthaya Sankar M. K

Professor.

Department of Internal Medicine,

Sri Manakula Vinayagar Medical College and Hospital,

Puducherry-605107, India.

E-mail:drmku2009@gmail.com

DOI: $10.14260 /$ jemds $/ 2018 / 626$ the QTc interval and decrease T-wave area and amplitude in electrocardiography (ECG). ${ }^{5}$ QT dispersion measurements (QTd and QTcd) as the most important independent predictors of global and cardiovascular mortality, QT interval dispersion could represent a summation of several adverse conditions present in the diabetic myocardium such as fibrosis, ischaemia, hypertrophy and dilatation, and autonomic dysfunction. ${ }^{6}$

\section{MATERIALS AND METHODS \\ Study Design}

A hospital-based case-control study.

\section{Study Area}

Sri Manakula Vinayagar Medical College and Hospital, Kalitheerthalkuppam.

Duration of Study- 3 months.

\section{Study Population}

The patients who attended the outpatient and admitted as an inpatient in Department of General Medicine.

\section{Sample}

Sample size is taken as per our convenience.

Case

Patients in age between 30 - 65 years who are coming to the General Medicine Department as a known case of type 2 
diabetics or newly diagnosed type 2 diabetics with any one of the following criteria-

- Symptoms of diabetes plus random blood glucose concentration $\geq 200 \mathrm{mg} / \mathrm{dL}(\geq 11.1 \mathrm{mmol} / \mathrm{L})$, or

- $\quad$ Fasting plasma glucose $\geq 126 \mathrm{mg} / \mathrm{dL} \mathrm{(} \geq 7.0 \mathrm{mmol} / \mathrm{L})$, or

- 2-h plasma glucose $\geq 200 \mathrm{mg} / \mathrm{dL}$ ( $\geq 11.1 \mathrm{mmol} / \mathrm{L})$ or

- Haemoglobin $\mathrm{A} 1 \mathrm{c} \geq 6.5 \%$.

Electrocardiography (ECG) will be taken from the diabetic patients and other blood investigations such as fasting lipid profile and $\mathrm{HbA} 1 \mathrm{C}$ were taken.

\section{Control}

Patients in age between 30 - 65 years coming to the General Medicine Department from other complaints are not a known diabetic, hypertensive or with coronary artery disease.

Electrocardiography (ECG) will be taken from the nondiabetic patients.

\section{Sampling}

Electrocardiography (ECG) will be taken from the diabetic/non-diabetic patients during the given span of time, after getting the informed consent from the patient (or patient's attender) and clearance from the Research and Ethical Committee. Patients were studied on both general and systematic examination. Blood tests such as fasting lipid profile and $\mathrm{HbA} 1 \mathrm{c}$ were taken.

\section{Instrumentation}

Standard resting 12-lead ECGs were recorded with the same commercial equipment (BPL Cardiart 9108 ) operated by one ECG technician at $25 \mathrm{~mm} / \mathrm{s}$ paper speed and $10 \mathrm{~mm} / \mathrm{mV}$ amplitude.

All the ECGs were analysed by One Person with no Knowledge of the Clinical Data-

1. QT intervals were measured manually from the onset of QRS complex to the end of the T-wave, defined as the return to the T-P baseline, independent of the polarity of the T-wave. When U-waves were present, the QT was measured to the nadir of the curve between the T- and U-waves. Whenever possible, three consecutive cycles in each of the 12 leads were measured with the mean QT interval calculated.

2. The RR interval to the measured QT was used to calculate the heart rate-corrected (QTc) interval using Bazett's formula (QTc $=$ QT/RR1/2).

3. The QT dispersion (QTd) defined was calculated as the difference between the maximum and the minimum QT interval obtained in any of the 12 electrocardiographic leads.

4. The QTc dispersion (QTcd), the difference between QTc maximum and QTc minimum.

\section{Ethical Consideration}

The Ethical approval will be obtained from the Institute Ethics Committee of SMVMC and H, Puducherry. All the ethical principles will be adhered in the study.

\section{Statistical Analysis}

Statistical analysis was performed in SPSS 16.0. The qualitative data were expressed as number (\%), while the continuous quantitative data as mean \pm standard deviation
(SD). Comparison between cases and controls is done by chisquare test and Fisher's exact test. QTc is measured through Bazett's formula and QT dispersion is calculated. P-value of $<0.05$ was considered significant, while $>0.05$ was considered not significant.

\section{RESULTS}

\begin{tabular}{|c|c|c|}
\hline & $\begin{array}{c}\text { Cases } \\
(\mathbf{N}=\mathbf{8 0})\end{array}$ & $\begin{array}{c}\text { Controls } \\
(\mathbf{N = 8 0 )}\end{array}$ \\
\hline Age (Mean \pm SD) & $52.7 \pm 11.9$ & $47.1 \pm 13.6$ \\
\hline $\begin{array}{c}\text { Duration of diabetes in years } \\
(\text { Mean } \pm \text { SD) }\end{array}$ & $8.2 \pm 6.2$ & - \\
\hline Gender & & \\
\hline Male & $53(66.3 \%)$ & $43(53.7 \%)$ \\
\hline Female & $27(33.7 \%)$ & $37(46.3 \%)$ \\
\hline \multicolumn{2}{|c|}{ Table 1. Characteristics of Cases and Controls }
\end{tabular}

In this study mean age $\geq 50$ years of age, mean duration of diabetes mellitus $\geq 8$ years, more than $\geq 50 \%$ are male.

\begin{tabular}{|c|c|c|c|c|c|}
\hline \multirow{2}{*}{} & \multicolumn{2}{|c|}{$\begin{array}{c}\text { Cases } \\
\text { (N=80) }\end{array}$} & \multicolumn{2}{c|}{$\begin{array}{c}\text { Controls } \\
\text { (N=80) }\end{array}$} & \multirow{2}{*}{ P value* } \\
\cline { 2 - 5 } & No. & $\mathbf{\%}$ & No. & $\mathbf{\%}$ & \\
\hline Smoking & 22 & $\{27.5\}$ & 13 & $\{16.3\}$ & 0.08 \\
\hline Alcohol use & 22 & $\{27.5\}$ & 24 & $\{30.0\}$ & 0.72 \\
\hline Family history & 20 & $\{25.0\}$ & 31 & $\{38.8\}$ & 0.06 \\
\hline $\begin{array}{c}\text { Orthostatic } \\
\text { hypotension }\end{array}$ & 37 & $\{46.3\}$ & 0 & $\{0.0\}$ & $<0.001$ \\
\hline HbA1c $\geq 6.5$ & 55 & $\{68.8\}$ & 0 & $\{0.0\}$ & $<0.001$ \\
\hline $\begin{array}{c}\text { Hypercholestero- } \\
\text { laemia }\end{array}$ & 11 & $\{13.8\}$ & 6 & $\{7.5\}$ & 0.19 \\
\hline Hypertriglyceridaemia & 21 & $\{26.3\}$ & 8 & $\{10.0\}$ & 0.007 \\
\hline Raised LDL & 3 & $\{3.8\}$ & 0 & $\{0.0\}$ & 0.24 \\
\hline QT dispersion & 32 & $\{40.0\}$ & 18 & $\{22.5\}$ & 0.016 \\
\hline Table 2. Comparison between Cases and Controls \\
\hline \multicolumn{5}{|c|}{} \\
\hline
\end{tabular}

*P value from chi-square test except for raised LDL (Fisher's exact test).

$\mathrm{P}$-value is more than 0.05 . This means it is not statistically significant. Wherever it is less than 0.05 , it is significant.

In this study variables such as orthostatic hypotension, hbA1c $\geq 6.5$, hypertriglyceridaemia has significant QT dispersion.

\begin{tabular}{|c|c|c|c|c|c|}
\hline \multirow{2}{*}{} & \multicolumn{2}{|c|}{$\begin{array}{c}\text { QT Dispersion } \\
\text { (N=50) }\end{array}$} & \multicolumn{2}{c|}{$\begin{array}{c}\text { Non-QT } \\
\text { Dispersion } \\
\text { (N=110) }\end{array}$} & $\begin{array}{c}\text { P } \\
\text { value* }\end{array}$ \\
\cline { 2 - 5 } & No. & \% & No. & \% & \\
\hline Smoking & 15 & $\{30.0\}$ & 20 & $\{18.2\}$ & 0.09 \\
\hline Alcohol use & 16 & $\{32.0\}$ & 30 & $\{27.3\}$ & 0.54 \\
\hline $\begin{array}{c}\text { Family } \\
\text { history }\end{array}$ & 17 & $\{34.0\}$ & 34 & $\{30.9\}$ & 0.69 \\
\hline $\begin{array}{c}\text { Orthostatic } \\
\text { hypotension }\end{array}$ & 28 & $\{56.0\}$ & 9 & $\{8.2\}$ & $<0.001$ \\
\hline HbA1c $\geq 6.5$ & 24 & $\{48.0\}$ & 31 & $\{28.2\}$ & 0.014 \\
\hline $\begin{array}{c}\text { Hypercholes } \\
\text {-terolaemia }\end{array}$ & 9 & $\{18.0\}$ & 8 & $\{7.3\}$ & 0.04 \\
\hline $\begin{array}{c}\text { Hypertriglyc } \\
\text {-eridaemia }\end{array}$ & 14 & $\{28.0\}$ & 15 & $\{13.6\}$ & 0.02 \\
\hline Raised LDL & 2 & $\{4.0\}$ & 1 & $\{0.9\}$ & 0.23 \\
\hline $\begin{array}{c}\text { Diabetes } \\
\text { mellitus }\end{array}$ & 32 & $\{64.0\}$ & 48 & $\{43.6\}$ & 0.016 \\
\hline Table 3. Comparison between QT Dispersion and Non-QT \\
Dispersion \\
\hline
\end{tabular}

${ }^{*} \mathrm{P}$ value from chi-square test except for raised LDL (Fisher's exact test). 
In this study if p-value is less than 0.05 , it is significant. Orthostatic hypotension, $\mathrm{HbA} 1 \mathrm{c} \geq 6.5$, hypercholesterolaemia and hypertriglyceridaemia are all significant.

\section{DISCUSSION}

As per result from the study, QT dispersion in type 2 diabetes mellitus is significant. ${ }^{7}$ Even in healthy individuals, hyperinsulinaemia-induced hypoglycaemia can prolong the QTc interval and decrease T-wave area and amplitude. ${ }^{8}$ Okin et $\mathrm{al}^{2}$ also found that both QTc prolongation and ST depression predicted all-cause mortality in patients with type 2 diabetes. It is associated with the increased mortality attributed to prolonged QT interval predisposing to ventricular arrhythmias, silent ischaemia and cardiac arrest. ${ }^{9}$ Prolonged QTc interval and duration of the disease over 10 years were the factors associated with higher risk.

The specificity of QTc prolongation in type 1 diabetes was found to be lower in a cohort $(62.5 \%)$ when compared to the specificity of $86 \%$ reported by Veglio et al ${ }^{10}$ among 3250 patients.

The pathophysiology of cardiovascular disease in diabetes mellitus, chronic hyperglycaemia and insulin resistance determine a significant alteration in the coagulation factors as well as increased platelet aggregation, leading to a prothrombotic state. Diabetes-induced increase of tissue factor levels activates thrombin converting fibrinogen into fibrin. Fibrin organisation is further enhanced due to high plasminogen activator inhibitor-1 (PAI-1) and reduced t-PA (Tissue plasminogen activator) levels. Increased $\mathrm{Ca} 2+$ content, thrombin stimulation as well as interaction with VWF (Von-Willebrand factor) via GPIIb/IIIa receptor lead to platelet shape change, granule release and aggregation. Release of MPs (Micro particles) from injured endothelium and circulating platelets contribute to accelerate thrombus development. Endothelial dysfunction precipitates rupture of the endothelial layer leading to exposure of collagen and VWF, thereby activating platelets and favouring vascular thrombosis. ${ }^{11}$

Exact mechanism of QTc prolongation is not defined clearly, but it has been suggested that some non-quantifiable sympathetic imbalance is responsible for QTc prolongation, as parasympathetics have little influence on QTc modulations. ${ }^{9}$

Recently ADA and American Academy of Neurology, considered the QTc interval to be specific, reproducible and standardised early test for autonomic function. ${ }^{12}$

This analysis suggested that cardiac dysautonomia can be picked up at the earliest by calculating QTc dispersion. ${ }^{13}$ Sawicki et al ${ }^{14}$ found QT dispersion to be the most important independent predictor of total mortality and also an independent predictor of cardiac and cerebrovascular mortality.

Christensen et al found high prevalence of QTc $440 \mathrm{~ms} 1 / 2$ (67\%) and of QT dispersion $50 \mathrm{~ms}$ (51\%) in a cohort study of 324 patients with type 2 diabetes and that prolonged QTc .

In diabetes patients, chest pain from silent ischaemia, unstable angina cannot be classical than compared to the other non-diabetes because of sympathetic overactivity of peripheral nervous system. ${ }^{15}$
The QT dispersion in type 2 diabetes mellitus is considered as poor-man's treadmill test. This can be taken as clinically significant. This can be used to identify the cardiovascular manifestation as early as possible.

From the study subjects with orthostatic hypotension, HbA1c $\geq 6.5$, hypertriglyceridaemia has more higher chance of cardiovascular disease compared than other variables.

\section{CONCLUSION}

Diabetes is an established risk factor for cardiovascular disease and is associated with the mortality. ${ }^{16}$ The increasing prevalence of type 2 diabetes, earlier onset of diabetes and aging of the population will result in an increasing prevalence of diabetes induced CV disease, suggesting that accurate noninvasive identification of diabetic individuals at high risk may play a role in the development of more effective preventive strategies for decreasing diabetes-related cardiovascular diseases. Although, increased QT interval and QT dispersion have been implicated as possible ECG predictors of cardiovascular diseases in type 2 diabetic patient.

\section{REFERENCES}

[1] Cardosoa C, Salles G, Bloch K, et al. Clinical determinants of increased QT dispersion in patients with diabetes mellitus. International Journal of Cardiology 2001;79(2-3):253-62.

[2] Okin PM, Devereux RB, Lee ET, et al. Electrocardiographic repolarization complexity and abnormality predict all-cause and cardiovascular mortality in diabetes: the strong heart study. Diabetes 2004;53(2):434-40.

[3] Stettler C, Bearth A, Allemann S, et al. QTc interval and resting heart rate as long-term predictors of mortality in type 1 and type 2 diabetes mellitus: a 23-year follow-up. Diabetologia 2007;50(1):186-94.

[4] Christensen PK, Gall MA, Major-Pedersen A, et al. QTc interval length and QT dispersion as predictors of mortality in patients with non-insulin-dependent diabetes. Scand J Clin Lab Invest 2000;60(4):323-32.

[5] Laitinen $\mathrm{T}$, Lyyra-Laitinen $\mathrm{T}$, Huopio $\mathrm{H}$, et al. Electrocardiographic alterations during hyperinsulinemic hypoglycemia in healthy subjects. Ann Noninvasive Electrocardiol 2008;13(2):97-105.

[6] Naas AA, Davidson NC, Thompson C, et al. QT and QTc dispersion are accurate predictors of cardiac death in newly diagnosed non-insulin-dependent diabetics: cohort study. Br Med J 1998;316(7133):745-6.

[7] Stern S, Sclarowsky S. The ECG in diabetes mellitus. Circulation 2009;120(16):1633-6.

[8] Cardoso CRL, Salles GF, Deccache W. QTc interval prolongation is a predictor of future strokes in patients with type 2 diabetes mellitus. Stroke 2003;34(9):2187-94.

[9] Chugh SP, Mittal P, Kumar S, et al. QT dispersion in patients of diabetes mellitus without manifest cardiac dysautonomia. JIMSA 2011;24(2):65-6.

[10] Veglio M, Bruno G, Borra M, et al. Prevalence of increased QT interval duration and dispersion in type 2 diabetic patients and its relationship with coronary heart disease: a population-based cohort. Journal of Internal Medicine 2002;251(4):317-24. 
[11] Paneni F, Beckman J, Creager MA, et al. Diabetes and vascular disease: pathophysiology, clinical consequences and medical therapy: part I. European Heart Journal 2013;34(31):2436-43.

[12] Arildsen H, May O, Christiansen EH, et al. Increased QT dispersion in patients with insulin-dependent diabetes mellitus. International Journal of Cardiology 1999;17(3):235-42.

[13] Psallas M, Tentolouris N, Cokkinos A, et al. QT dispersion: comparison between diabetic and nondiabetic individuals and correlation with cardiac autonomic neuropathy. Hellenic J Cardiol 2006;47(5):255-62.
[14] Sawicki PT, Kiwitt S, Bender R, et al. The value of QT interval dispersion for identification of total mortality risk in non-insulin-dependent diabetes mellitus. Journal of Internal Medicine 1998;243(1):49-56.

[15] Pappachan JM, Sebastian J, Bino BC, et al. Cardiac autonomic neuropathy in diabetes mellitus: prevalence, risk factors and utility of corrected QT interval in the ECG for its diagnosis. Postgrad Med J 2008;84(990):205-10.

[16] Rana BS, Band MM, Ogston S, et al. Relation of QT interval dispersion to the number of different cardiac abnormalities in diabetes mellitus. Am J Cardiol 2002;90(5):483-7. 